\title{
IS HIGH-RISK AIS SECURITY INVESTMENT A NO-WIN SITUATION? THE INFLUENCE OF ATTITUDES, NORMS, EFFICACY AND PRIOR OUTCOMES
}

Gary Fleischman ${ }^{1}$, Sean Valentine ${ }^{2}$, Mary Curtis ${ }^{3}$, Partha S Mohapatra ${ }^{4}$

${ }^{1}$ Texas Tech University, ${ }^{2}$ University of North Dakota, ${ }^{3}$ University of North Texas, ${ }^{4} \mathrm{CSU}$-Sacramento

Objective: To examine the psychological drivers (i.e., perceived attitudes, norms, and efficacy personal agency) of the managerial reasoning process regarding high-risk investments in AIS security.

Introduction: While recent data breaches underscore importance of IS security, costs of necessary security may be prohibitive, forcing CFOs to make difficult financial and moral tradeoffs. Hence, based on the Integrated Behavioral Model (Montaño and Kasprzyk 2015), our specific research questions about risky investments in IS security focus on the role of manager perceptions relating to 1) attitudes about the morality and importance of an AIS hacking risk investment scenario, 2) norms representing how society and peers would likely evaluate the depicted investment trade-off, and 3) personal agency relating to efficacy and control.
Hypothesized relationships:

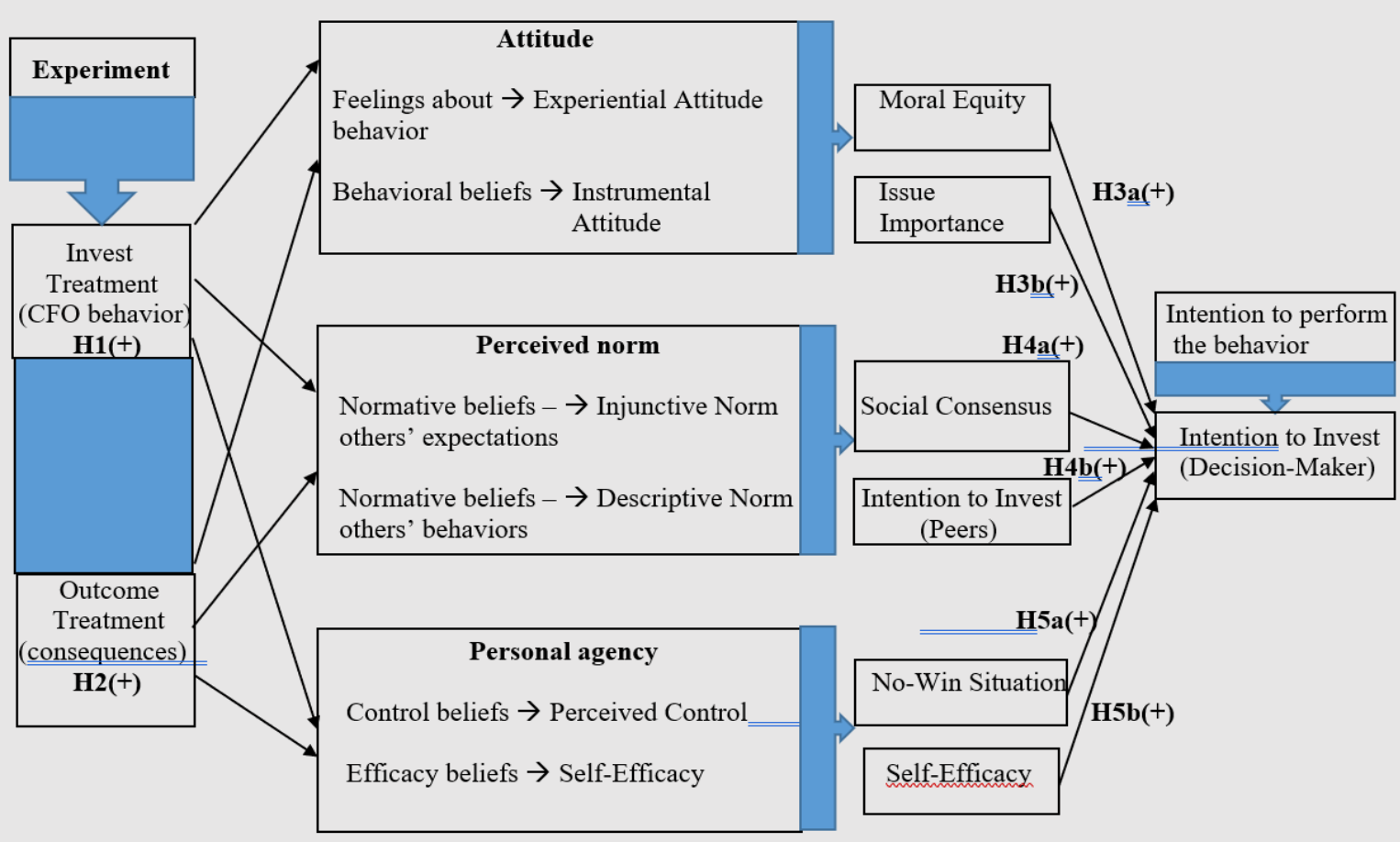

Methods: We use a scenario that involves IS security investment decisions made by a Chief Financial Officer (CFO).

Use a 2x2 experimental randomized design. Four treatments: The observed CFO, 1. Invested in security and had a favorable organizational outcome; 2 . Invested in security and had an unfavorable organizational outcome; 3 . Did not invest in security and had an unfavorable organizational outcome, and 4 . Did not invest in security and had a favorable organizational outcome. Graduate students from B-Schools (with average experience of 5.5. years) participated in our study.

\section{Findings \& Conclusion:}

We find that managers are more likely to invest similarly to scenario CFOs who choose to invest in protective security (supporting $\mathrm{H} 1$ ), and are also more likely to invest in a similar manner as CFOs who invest in protective security when the firm is hacked, supporting $\mathrm{H} 2$. Findings also support other hypotheses except for H3b (Issue Importance) and H5b (Self-Efficacy). Findings suggest:

- Middle manager participants intend to invest in a similar (dissimilar) manner as the scenario CFO when the CFO chooses to invest (not invest) in needed security.

- Perceived norms from peers and society drive participant investments in AIS, and serially mediate organizational outcomes.

- Peer versus societal influence dominance varies depending on experimental context.

- Perceptions that the situation overall reflects a no-win situation also drives managerial investment decisions.

- Confident independent thinkers make more appropriate investment decisions to protect sensitive client data despite possible harm to personal cost cutting reputations. 